\title{
Toxicity of Insecticide Carrier Solvent: Effect of Xylene on Hemolymph Biochemical Parameters in Blaberus giganteus L.
}

\author{
Justyna Maliszewska*, Eugenia Tegowska \\ Department of Animal Toxicology, Faculty of Biology and Environmental Protection, \\ Nicolaus Copernicus University, Toruń, Poland
}

Received: 30 June 2017

Accepted: 21 September 2017

\begin{abstract}
Pesticide formulations contain solvents and compounds that improve dispersion and absorption. One of the solvents employed in pesticide concentrates is xylene, an aromatic hydrocarbon widely used in paints, lacquers, or glues. This study was undertaken to evaluate the possible toxic effect of xylene on the giant cave cockroach Blaberus giganteus L. and its role in insecticide formulation toxicity. Different biochemical parameters were determined in cockroaches treated with xylene or pyrethroid formulation, in which xylene is used as a solvent. Xylene induced changes in sugar content and the level of lipid peroxidation similar to changes elicited by treatment with insecticide formulation. The present study shows that xylene induces organismal toxicity in Blaberus giganteus and should not be regarded as a carrier solvent with little biological activity. Since pesticides are always used with adjuvants that can change their toxicity, pesticide formulations should be studied as mixtures for toxic effect.
\end{abstract}

Keywords: acetylcholinesterase activity, Blaberus giganteus, insecticide, oxidative stress, xylene

\section{Introduction}

Xylene is an aromatic hydrocarbon occurring naturally in petroleum, coal, and wood tar. It is one of the top 30 chemicals produced in the United States in terms of volume. The annual production of xylene is estimated to be 16 million tons. Xylene is widely used as a solvent for paints, lacquers, glues, and pesticides, as well as in histological laboratories. Xylene is also found in airplane fuel, gasoline, and cigarette smoke [1-2]. In Poland, the threshold limit value for workers is $100 \mathrm{mg} / \mathrm{m}^{3}$. It was estimated that hospital laboratory workers may be exposed to xylene in concentrations

*e-mail: ojustyna@umk.pl reaching $1,740 \mathrm{mg} / \mathrm{m}^{3}$, while printing house workers may be exposed to xylene in concentrations of about 130 $\mathrm{mg} / \mathrm{m}^{3}$ [3]. One can also come into contact with xylene through cigarette smoke, paints, automobile exhaust, and a variety of other consumer products [2].

Commercial products contain non-insecticidal ingredients that act as adjuvants, solvents, emulsifiers, or preservatives and which are not needed to be identified on the product label unless classified as highly toxic [4]. Many insecticide formulations contain 25 to 75 percent of solvent mixtures, and xylene and other aromatic hydrocarbons are frequently employed as solvents in pesticide concentrates [5]. Brattsten and Wilkinson [6] in experiments performed on southern armyworm demonstrated that, paradoxically, the carrier solvent in which the insecticide is formulated may aid in the 
survival of the target pest. This is due to the induction of an insect's mixed-function oxidase system, which takes part in the metabolism of insecticides. They conclude that the solvent carriers should not be regarded as ingredients with no biological activity. Interestingly, xylene was used as a DDT emulsifier applied for the control of mosquitoes, flies, and other insects in emulsion concentrates adapted for armed forces [7]. The Pesticide Action Network Database presents 17 chemicals that contain xylene and which are registred as adjuvants, solvents, microbiocides, herbicides, fungicides, insect repellents, and insecticides. None of them are listed as toxic by WHO acute hazard or U.S. Environmental Protection Agency acute toxicity rankings [8].

The aim of our study was to assess the toxicity of the pyrethroid insecticide solvent xylene on adult individuals of Blaberus giganteus L. It is of interest whether xylene-induced changes in various hemolymph biochemical parameters of cockroaches differ from changes induced by the application of pyrethroid insecticide formulation.

\section{Material and Methods}

\section{Insects}

Experiments were performed on adult individuals of the giant cave cockroach Blaberus giganteus L. from a laboratory colony. Cockroaches were kept at $\sim 25^{\circ} \mathrm{C}$ and natural photoperiod in glass containers. They were fed with oat flakes, apples, and water ad libitum. Experiments were performed separately on males and females. In each experimental series 10 individuals of each sex were examined.

\section{Substances Tested}

The insecticide used for experiments was pyrethroid Bulldock 025EC (Makhteshim Chemical Works Ltd; Israel) with beta-cyfluthrin $(2.7 \%)$ as an active substance. Since the main component of insecticide Bulldock 025EC mixture was xylene (80-90\%; Sigma Aldrich), this solvent in $80 \%$ concentration was used in the experiments. Cockroaches were intoxicated with $10 \mu \mathrm{l}$ of the tested substances: $1 /$ Bulldock $025 \mathrm{EC}$, in which xylene is the main solvent or $2 / 80 \%$ xylene only, under the wings, on the mesothorax. The control group received only water.

\section{Hemolymph Biochemical Parameters}

Three days after exposure to the tested substances, $\mathrm{pH}$ of the exposed insects hemolymph, content of sugars in the hemolymph, the level of lipid peroxidation, and acetylcholinesterase activity was determined.

Hemolypmph was obtained from the decapitated individuals. Hemolymph $\mathrm{pH}$ was measured on $10 \mu \mathrm{l}$ samples collected with glass microcapillary tubes. Samples were immediately transferred to the $\mathrm{pH}$-meter (B 712 Laquatwin Compact pH meter, Horiba Scientific, New Jersey, USA), which was calibrated with standard calibration buffers before each experimental series.

The content of sugars in cockroach hemolymph was determined using colorimetric method phenol-sulfuric acid according to DuBois et al. [9]. $2 \mu \mathrm{l}$ of examined cockroach hemolymph (different individuals from that used for hemolymph $\mathrm{pH}$ measurements) was diluted in ethyl alcohol (60\%) and centrifuged at $10,000 \mathrm{x} \mathrm{g}$ for $5 \mathrm{~min}$ (MPW-55, Med Instruments). Then $0.5 \mathrm{ml}$ of supernatant was pippeted into a tube and mixed with $0.5 \mathrm{ml}$ of $5 \%$ phenol and $2.5 \mathrm{ml}$ of concentrated sulfuric acid. The absorbance was measured at $490 \mathrm{~nm}$ (Shimadzu UV-VIS 1700 Spectrophotometer). The content of sugar was read from the standard curve for $\mathrm{D}(+)$ trehalose.

To assess lipid peroxidation we used spectrophotometric quantitation of malondialdehyde (MDA) by thiobarbituric reaction [10-11]. The examined cockroaches were homogenized in cold phosphate buffer, and next thiobarbituric acid solution $(0.37 \%$ in $0.25 \mathrm{M} \mathrm{HCl})$ and trichloroacetic acid solution $(15 \%$ in $0.25 \mathrm{M} \mathrm{HCl}$ ) were added. The mixture was placed for 20 minutes in a boiling water bath, then cooled and transferred to Eppendorf tubes and centrifuged for 15 minutes $\left(10,000 \mathrm{x}\right.$ g; $\left.25^{\circ} \mathrm{C}\right)$. Supernatant absorbance was measured at $532 \mathrm{~nm}$. Malondialdehyde concentration was determined based on milimolar absorption coefficient $\left(156 \mathrm{mmol}^{-1} \cdot \mathrm{L} \cdot \mathrm{cm}^{-1}\right)$.

Acetylcholinesterase (AChE) activity was determined colometrically based on the modified method by Ellman et al. [12]. Intoxicated cockroaches were homogenized in cold phosphate buffer ( $\mathrm{pH}$ 7.2). Homogenates were centrifuged at $3,000 \mathrm{x}$ g for $10 \mathrm{~min}$ in centrifuge (MPW-55, Med Instruments). $30 \mu \mathrm{l}$ of the supernatant was then added to $0.075 \mathrm{M}$ acetylthiocholine iodide and 0.01M 5,5'-dithiobis-(2-nitrobenzoic acid) (DTNB). Absorbance at $412 \mathrm{~nm}$ was measured for three minutes (Shimadzu UV-VIS 1700 Spectrophotometer). Rate of acetylthiocholine hydrolysis was calculated from the equation determined by Ellman et al. [12].

\section{Data Analysis}

Two-way ANOVA with data ( $\mathrm{pH}$, MDA content, sugar content, or AChE activity) as dependent variable and sex (male or female) and treatment (xylene or insecticide) as fixed factors revealed significant differences in obtained results between Blaberus sexes for MDA concentration (two-way ANOVA: $\mathrm{F}_{1.50}=4.23$, $P=0.021$ ) and AChE activity (two-way ANOVA: $\left.\mathrm{F}_{1.40}=3.95, P=0.028\right)$. Therefore, all analyses were performed separately on males and females. Prior to analysis, data were tested for normality (KolmogorovSmirnov test) and homogeneity of variances (Levene's test). Data that met assumptions of one-way analysis of variance were tested with ANOVA and post hoc Tukey 
Table 1. Changes in hemolymph biochemical parameters in Blaberus giganteus treated with xylene and insecticide Bulldock 025 EC.

\begin{tabular}{|c|c|c|c|c|c|c|}
\hline \multirow{2}{*}{} & \multicolumn{2}{|c}{ Control } & \multicolumn{2}{c|}{ Xylene } & \multicolumn{2}{c|}{ Insecticide } \\
\cline { 2 - 7 } & Males & Females & Males & Females & Males & Females \\
\hline $\mathrm{pH}$ of hemolymph & $6.92 \pm 0.03$ & $6.98 \pm 0.03$ & $\underline{6.92 \pm 0.05}$ & $\underline{6.85 \pm 0.06}$ & $\mathbf{7 . 0 5} \pm \mathbf{0 . 0 3} *$ & $\mathbf{7 . 1 1} \pm \mathbf{0 . 0 3 *}$ \\
\hline MDA concentration $(\mu \mathrm{mol} / \mathrm{ml} \pm \mathrm{SE})$ & $0.31 \pm 0.07$ & $0.95 \pm 0.15$ & $\underline{\mathbf{0 . 9 5} \pm \mathbf{0 . 0 9} *}$ & $1.40 \pm 0.81$ & $\mathbf{0 . 6 3} \pm \mathbf{0 . 0 8 *}$ & $\mathbf{3 . 9 9} \pm \mathbf{1 . 6 9 *}$ \\
\hline $\begin{array}{c}\text { Sugar concentration in the hemolymph } \\
(\mathrm{mg} / 100 \mathrm{ml} \pm \mathrm{SE})\end{array}$ & $669 \pm 277$ & $1,590 \pm 742$ & $\mathbf{3 , 5 9 6} \pm \mathbf{1 , 0 9 6 *}$ & $2,667 \pm 649$ & $3,297 \pm 1400$ & $2,878 \pm 1149$ \\
\hline
\end{tabular}

$* P<0.05$ was considered statistically significant compared to the untreated group. Underlined results show statistical significance $(P<0.05)$ between xylene- and insecticide-treated cockroaches.

test. Mann-Whitney U test was used as a nonparametric test in case of data that were not normally distributed. All analyses were performed with IBM SPSS 22. Data are present as mean $\pm \mathrm{SE}$.

\section{Results}

Blaberus giganteus L. exposed to pyrethroid insecticide and its main component, xylene, revealed significant changes in hemolymph biochemical parameters (Table 1).

$\mathrm{pH}$ of the hemolymph of insecticide-treated insects increased in both sexes (ANOVA: $\mathrm{F}_{2.32}=3.33, P=0.05$ for males and $\mathrm{F}_{2.33}=8.443, P=0.001$ for females). After treatment with xylene, changes in cockroach hemolymph $\mathrm{pH}$ were not significant. However, we observed a significant decrease in hemolymph $\mathrm{pH}$ in xylene-treated insects compared to insecticide-treated cockroaches (Tukey test: $P=0.029$ for males and $P=0.001$ for females).

The level of lipid peroxidation significantly increased in treated insects. Males showed the highest MDA

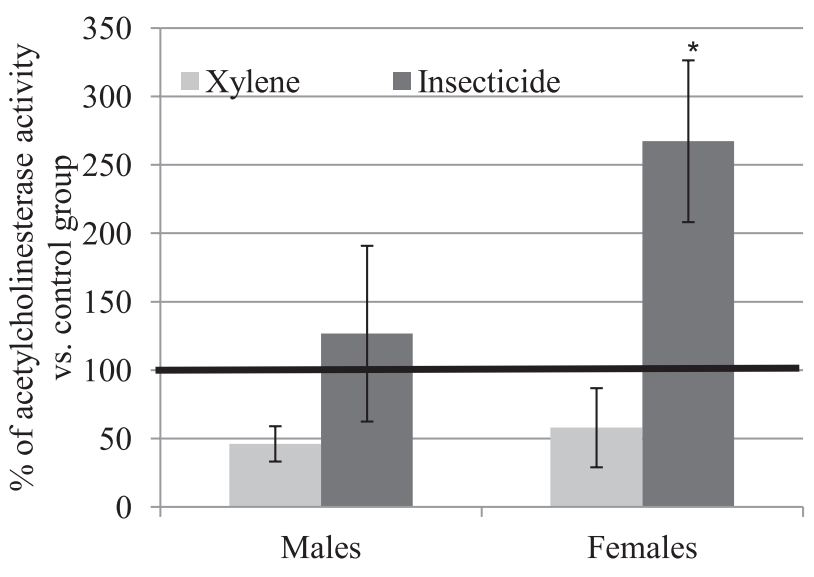

Fig. 1. Acetylcholinesterase activity of Blaberus giganteus males and females exposed to xylene and Bulldock insecticide (percentage compared to control group). The thick black line indicates the level of acetylcholinesterase activity in untreated insects $(100 \%)$.

*Means significantly different from control group (ANOVA; post-hoc Tukey test; $* P<0.05)$. concentration after treatment with xylene (ANOVA: $\mathrm{F}_{2.26}=16.51, P=0.00002$; Tukey test: $\left.P=0.00001\right)$, which was also significantly higher from cockroaches treated with insecticide (Tukey test: $P=0.02$ ). On the other hand, the highest level of lipid peroxidation in females was observed after treatment with pyrethroid (T-test: $\mathrm{t}_{14,5.86}=-2.36, P=0.03$ ).

Sugar concentration in cockroach hemolymph significantly increased in xylene-treated males (MannWhitney test: $\mathrm{U}=3.0, \mathrm{Z}=-2.2, P=0.03$ ). In females, changes in trehalose content after intoxication were not significant.

Xylene treatment did not affect acetylcholinesterase activity of treated cockroaches significantly, although a tendency to decreased activity was observed (about 50\% of control group enzyme activity) (Fig. 1). Insecticide treatment resulted in increased activity of $\mathrm{AChE}$ in females only (ANOVA: $\mathrm{F}_{225}=7.691, P<0.01$, Tukey test: $P=0.015$ compared to control group and $P=0.003$ compared to xylene-treated females).

Blaberus individuals treated with xylene showed $10 \%$ (females) and 13\% (males) mortality 72 hours after intoxication, and this was not statistically different from mortality of insects exposed to pyrethroid $\left(19 \%\right.$ for females, Kruskall-Wallis test: $\chi^{2}=0.86$, $\mathrm{df}=2, P=0.65$; and $41 \%$ for males, KruskallWallis test: $\chi^{2}=2.48, \mathrm{df}=2, P=0.29$ ).

\section{Discussion}

The present study shows that xylene-induce organismal toxicity in Blaberus giganteus L. and should not be regarded as a carrier solvent with little biological activity. Xylene treatment resulted in significant changes of hemolymph biochemical parameters of cockroaches. The level of lipid peroxidation and sugar content in the hemolymph increased in Blaberus males and females. What is more, a similar trend (increase) was observed after treatment with pyrethroid insecticide, and the results of MDA and sugar concentration between xylene and pesticide treatment were generally not significantly different. This shows that xylene demonstrates high toxicity to Blaberus giganteus L., similar to that observed after treatment with insecticide. This is also reflected in the mortality of intoxicated insects, which 
was not significantly different between xylene and insecticide-treated cockroaches. However, it should be noted that after pyrethroid treatment cockroaches were severely paralyzed. This paralysis was irreversible and ended with the treated insects' death 14 days after intoxication.

Increased lipid peroxidation after xylene treatment was also observed in Drosophila melanogaster, where a 2,5-fold increase in MDA concentration was observed 48 hours after exposure [13]. Neurotoxicity and hepatotoxicity of xylene is a result of the induction of apoptosis and the generation of reactive oxygen species [14]. It was shown that antioxidants prevent the oxidative effects of xylene in the central nervous system in animals [15]. Revilla et al. [16] demonstrated that xylene cell toxicity is a result of mitochondrial uncoupling via ATP depletion and mitochondrial reactive oxygen species generation. This also results in lower energy reserves for detoxification processes.

Significant differences between xylene and pesticide treatment were observed in the case of hemolymph $\mathrm{pH}$ and acetylcholinesterase activity of Blaberus individuals, where insecticide effect was greater than in xylene-treated cockroaches. Although the molecular basis for pyrethroid neurotoxicity is connected with their action on voltage gated sodium channels, some reports show pyrethroid action on acetylcholinesterase activity. Rats treated with $\mathrm{LD}_{50}$ of permethrin and cypermethrin showed elevated activity of AChE in specific regions of the brain and inhibited activity in other regions [17]. Some reports show that bifenthrin treatment induced a decrease of AChE activity [18], while others show no effect of this pyrethroid on AChE activity in rats [19]. Xylene was reported to cause changes in neuronal cells, such as increased levels of dopamine or catecholamine and reduced axonal transport in rat brains [20-21]. This solvent also caused a $10-50 \%$ reduction of human erythrocyte membrane acetylcholinesterase activity [22], which also was observed in Blaberus (50\% reduction in activity).

It is interesting to observe the low sensitivity of Blaberus giganteus L. to pyrethroid formulation used in the experiments. Because of low mortality after Bulldock 025 EC treatment, $\mathrm{LD}_{50}$ doses could not be determined in preliminary experiments, therefore undiluted formulation was used (each cockroach was treated with $25 \mu \mathrm{g}$ of beta-cyfluthrin). This resulted in paralysis, and mortality reached around 50\% after 6 days of treatment. In comparison, $\mathrm{LD}_{50}$ for different insect species are considerably lower, e.g., $0.2 \mu \mathrm{g} / \mathrm{g}$ in a susceptible strain of German cockroach Blattella germanica L. [23], $0.5 \mu \mathrm{g} / \mathrm{g}$ in bees Apis mellifera L. [24], $0.31 \mu \mathrm{g} / \mathrm{insect}$ in Anopheles sinensis Wiedemann 1828 [25], or 1-16 $\mu \mathrm{g} /$ insect in a pyrethroid-resistant strain of Helicoverpa armigera (Hübner) [26]. Another experiment also showed residual sensitivity of Blaberus giganteus to indoxacarb, which is a sodium channel blocker (the same molecular target for action as pyrethroids-sodium channel, but different action on this structure). Doses as high as $84 \mu \mathrm{g} /$ insect (topical) did not cause any mortality over 7 days of observation, while topical $\mathrm{LD}_{50}$ for Blatella germanica $\mathrm{L}$. is set to be $1.75 \mu \mathrm{g} / \mathrm{g}$ [27].

It is worth emphasizing the differences between males and females in response to insecticides. Female responses to pyrethroid were significantly higher in the case of acetylcholinesterase activity and lipid peroxidation. Pyrethroids are highly lipid soluble, and Blaberus females have more fat than males. The weight of isolated body fat in males comprise $\sim 5 \%$ of its body weight, and $\sim 15 \%$ in females (personal observation). Females are heavier than males (mean body weight of individuals used for experiments was $9.9 \mathrm{~g}$ for females and $5.5 \mathrm{~g}$ for males). This may result in better penetration of pyrethroid in females. According to our knowledge, this is the first mention of different responses to pyrethroid or xylene between cockroach sexes. Most cited articles are based on experiments performed on males only [e.g., 16-17; 28] or without sex division [30].

Commercial preparations of pesticides contain the active ingredient and solvents or compounds that improve absorption or dispersion. These components are usually regarded as inactive constituents and their toxicity is often not included in the debate about possible unfavorable effects. However, Skandrani et al. [29] demonstrated that commercial pesticide formulations are more toxic than pure active components, with even 150 times higher toxicity for bifenthrin formulations. Peixoto [30] showed that "inert" ingredients used in Roundup herbicide are responsible for toxicity on the level of mitochondrial bioenergetics. Diacetone alcohol, which is a dispersant solvent in Adonis 3UL insecticide, was demonstrated to be highly toxic to zebra finch, and contributed to the toxicity of insecticide formulation. Interestingly, this solvent is listed as "inert of unknown toxicity" by the U.S. EPA [28]. Solvents have also played a major role in dimethoate toxicity [31] and were demonstrated to be more toxic to human hepatic and embryonic cells than glyphosate formulations [32-33].

Our study has indicated that evaluating pesticide formulation toxicity should not be assessed only on active ingredient toxicity.

\section{Conclusions}

1) The present study shows that xylene-induce organismal toxicity in Blaberus giganteus L., which demonstrated elevated sugar content in the hemolymph and high levels of malondialdehyde, is a marker of lipid peroxidation.

2) Changes in levels of malondialdehyde and sugar content in hemolymphs were generally similar to changes induced by treatment with insecticide in which xylene is a main solvent.

3) There are significant differences in response to chemicals between Blaberus males and females. 
4) Xylene, used as an insecticide solvent, should not be regarded as an ingredient with little biological activity.

\section{Acknowledgements}

Our research was funded by statutory funds of the Faculty of Biology and Environmental Protection Nicolaus Copernicus University [No. 182/2016].

\section{References}

1. KANDYALA R., RAGHAVENDRA S.P.C., RAJASEKHARAN S.T. Xylene: an overview of its health hazards and preventive measures. J. Oral Maxifollac. Pathol. 14 (1), 1, 2010.

2. RAJAN S.T., MALATHI N. Health hazards of xylene: a literature review. J. Clin. Diagn. Res. 8 (2), 271, 2014.

3. LIGOCKA D. Ksylen - mieszanina izomerów (Xylene all isomers). Podstawy i metody oceny środowiska pracy $\mathbf{4}$, 139, 2007 [In Polish].

4. BEGGEL S., WERNER I., CONNON R.E., GEIST J.P. Sublethal toxicity of commercial insecticide formulations and their active ingredients to larval feathed minnow (Pimephales promelas). Sci. Total Environ. 408 (16), 3169, 2010.

5. SARWAR M. Commonly available commercial insecticide formulations and their applications in the field. Int. J. Mat. Chem. Phys. 1 (2), 116, 2015.

6. BRATTSTEN L.B., WILKINSON C.F. Insecticide solvents: interference with insecticidal action. Science $\mathbf{1 0}$ (196), 1211, 1977.

7. JONES H.A., FLUNO H.J. DDT-xylene emulsions for use against insects affecting man. J. Econ. Entomol. 39 (6), 735, 1946.

8. KEGLEY S.E., HILL B.R., ORME S., CHOI A.H., PAN Pesticide Database, Pesticide Action Network North America. http://www.pesticideinfo.org, 2014 [accessed 21 06 2016].

9. DUBOIS M., GILLES K.A., HAMILTON J.K., REBERS P.A., SMITH F. Colorimetric method for determination of sugars and related substances. Anal. Chem. 28, 350, 1956.

10. SUNDERMAN F.W., MARZOUK A., HOPFER S.M., ZAHARIA O., REID M.C. Increased lipid peroxidation in tissues of nickel chloride - treated rats. Ann. Clin. Lab. Sci. 15, 229, 1985.

11. BARTOSZ G. The second face of oxygen. Free radicals in nature. $2^{\text {nd }}$ ed., PWN: Warszawa, Poland, 358, 2013 [In Polish].

12. ELLMAN G.L., COURTNEY D.K., ANDRES V., FEATHERSTONE R.M. A new and rapid colorimetric determination of acetylcholinesterase activity. Biochem. Pharmacol. 7, 88, 1961.

13. SINGH M.P., KRISHNA REDDY M.M., MATHUR N., SAXENA D.K., CHOWDHURI D.K. Induction of hsp70, hsp60, hsp83, hsp26 and oxidative stress markers in benzene, toluene and xylene exposed Drosophila melanogaster: Role of ROS generation. Toxicol. Appl. Pharmacol. 235 (2), 226, 2009.

14. SONG B.B., YANG E.J., KIM B.M., LEE J.S., YUN C.J., IM Y.B., KIM I.S. The effects of benzene and toluene on leukotactin-1-induced migration of EoL-1 cells. Moll. Cell. Toxicol. 7, 140, 2011.
15. GAO J., RUAN H., QI X., GUO X., ZHENG J., LIU C., FANG Y., HUANG M., XU M., SHEN W. Increased apoptosis and abnormal visual behavior by histone modifications with exposure to para-xylene in developing Xenopus. Neurosci. 331, 177, 2016.

16. REVILLA A.S., PESTANA C.R., PARDO-ANDREU G.L., SANTOS A.C., UYEMURA S.A., GONZALES M.E., CURTI C. Potential toxicity of toluene and xylene evoked by mitochondrial uncoupling. Toxicol. In Vitro $\mathbf{2 1}$ (5), 782, 2007.

17. RAO G.V., RAO K.S.J. Modulation in acetylcholinesterase of rat brain by pyrethroids in vivo and in vitro kinetic study. J. Neurochem. 65 (5), 2259, 1995.

18. DAR M.A., KHAN A.M., RAINA R., BEIGH S.A., SULTANA M. Effect of repeated oral administration of bifenthrin antioxidant status and acetylcholinesterase activity in brain of rats. Toxicol. Environ. Chem. 97 (7), 961, 2015.

19. DAR M.A., RAINA R., MIR A.H., SULTANA M., PANKAJ N.K. Effect of dermal application of bifenthrin on acetylcholinesterase and oxidative stress indices in rat blood, lung and kidney. Proc. Natl. Acad. Sci. India 85 (2), 431, 2015.

20. NIAZ K., BAHADAR H., MAQBOOL F., ABDOLLAHI M. A review of environmental and accupational exposure to xylene and its health concerns. EXCLI J. 14, 1167, 2015.

21. GUTHRIE O.W., WONG B.A., MCINTURF S.M., REBOULET J.E., ORTIZ P.A., MATTIE D.R. Background noise contributes to organic solvent induced brain dysfunction. Neural Plast. 2016, 8742725, 2016.

22. KORPELA M., TÄHTI H. Effects of organic solvents on erythrocyte membrane acetylcholine esterase activity. In Archives of Toxicology; Chamber P.L, Cholnoky E., Chambers C.M., Springer-Verlag: Berlin, Germany, Suppl. 8, 148, 1985.

23. CHAI R., LEE C. Insecticide resistance profiles and synergism in field populations of the German cockroach (Dictyoptera: Blattellidae) from Singapore. J. Econ. Entomol. 103 (2), 460, 2010.

24. ZHU Y.C., ADAMCZYK J., RINDERER T., YAO X., DANKA R., LUTTRELL R., GORE J. Spray toxicity risk potential of 42 commonly used formulations of row crop pesticides to adult honey bees (Hymenoptera: Apidae). J. Econ. Entomol. 108 (6), 2640, 2015.

25. SHIN E.H., PARK C., KIM H.K., LEE D.K., KIM S.I., KANG H., CHANG K.S., Insecticide susceptibility of Ephemera orientalis (Ephemeroptera: Ephemeridae) and two mosquito species, Anopheles sinensis and Culex pipiens in the Republic of Korea. J Asia-Pac. Entomol. 14 (3), 233, 2011.

26. KARAAĞAÇ S.U., KONUŞ M., BÜYÜK M. Determination of susceptibility levels of Helicoverpa armigera (Hübner) (Noctuidae: Lepidoptera) strains collected from different regions to some insecticides in Turkey. J. Entomol. Res. Soc. 15 (1), 37, 2015.

27. GONDHALEKAR A.D., SONG C., SCHARF M.C. Development of strategies for monitoring indoxacarb and gel bait susceptibility in the German cockroach (Blattodea: Blattellidae). Pest. Manag. Sci. 67, 262, 2011.

28. KITULAGODAGE M., ASTHEIMER L.B., BUTTEMER W.A. Diacetone alcohol, a dispersant solvent, contributes to acute toxicity of a fipronil-based insecticide in a passerine bird. Ecotoxicol. Environ. Saf. 71 (2), 597, 2008.

29. SKANDRANI D., GAUBIN Y., VINCENT C., BEAU B., MURAT J.C., SOLEILHAVOUP J.P., CROUTE F. Relationship between toxicity of selected insecticides 
and expression of stress proteins (HSP, GRP) in cultured human cells: Effects of commercial formulations versus pure active molecules. Biochim Biophys Acta 1760 (1), 95, 2006.

30. PEIXOTO F. Comparative effects of the Roundup and glyphosate on mitochondrial oxidative phosphorylation. Chemosphere 61 (8), 1115, 2005.

31. EDDLESTON M., STREET J.M., SELF I., THOMPSON A., KING T., WILLIAMS N., NAREDO G., DISSANAYAKE K., YU L.M., WOREK F., JOHN H., SMITH S., THIERMAN H., HARRIS J.B., CLUTTON R.E. A role of solvents in the toxicity of agricultural organophosphorus insecticides. Toxicology 294 (2-3), 94, 2012.

32. MESNAGE R., BERNAY B., SÈRALINI G.E. Ethoxylated adjuvants of glyphosate-based herbicides are active principles of human cell toxicity. Toxicology 313 (2-3), 122, 2013.

33. MARTINI C.N., GABRIELLI M., CODESIDO M.M., VILA M.C. Glyphosate-based herbicides with different adjuvants are more potent inhibitors of 3T3-L1 fibroblast proliferation and differentiation to adipocytes than glyphosate alone. Comp. Clin. Pathol. 25, 607, 2016. 